\title{
First occurrence of the problematic vetulicolian Skeemella clavula in the Cambrian Marjum Formation of Utah, USA
}

\author{
Julien Kimmig ${ }^{1,2}$ \\ Wade W. LeIBACH ${ }^{1,3}$ \\ Bruce S. LIEBERMAN ${ }^{1,4}$
}

Abstract: The Cambrian Marjum Formation of western Utah (USA) preserves a diverse soft-bodied fauna from the upper Drumian that is slightly younger than the well-known Burgess Shale. While the Marjum is dominated by arthropods, animals belonging to a variety of phyla have been found. Here, we document the second occurrence of the rare, enigmatic taxon Skeemella clavula, which was previously thought to be restricted to the Pierson Cove Formation of the Drum Mountains. The occurrence in the Marjum represents a new preservational setting, as well as a slightly younger deposit. The new specimens also expand the number of known specimens to three. In addition, they improve understanding of the morphology of this representative of the problematic phylum Vetulicolia.

\section{Key-words:}

- Burgess Shale-type preservation;

- Great Basin;

- Vetulicolia;

- Miaolingian;

- Drumian;

- Problematica

Citation: Kimmig J., Leibach W.W. \& Lieberman B.S. (2020).- First occurrence of the problematic vetulicolian Skeemella clavula in the Cambrian Marjum Formation of Utah, USA.- Carnets Geol., Madrid, vol. 20 , no. 10 , p. $215-221$.

Résumé : Première occurrence du Vetulicolia problématique Skeemella clavula dans la Formation cambrienne de Marjum Formation d'Utah, É.U.A.- Dans l'ouest de I'Utah (É.U.A.), la Formation cambrienne de Marjum préserve une faune diversifiée d'animaux à corps mou dans le Drumien supérieur, une faune légèrement plus jeune que celle des fameux Schistes de Burgess. Alors que la Formation de Marjum est dominée par les arthropodes, des animaux appartenant à différents phylums ont également été découverts. Nous illustrons ici la seconde occurrence de Skeemella clavula, un rare et énigmatique taxon dont on pensait précédemment qu'il n'était présent que dans la Formation de Pierson Cove des Montagnes de Drum (N Utah). Leur présence dans la Formation de Marjum représente un nouveau milieu de conservation, ainsi qu'un dépôt légèrement plus jeune. Les nouveaux spécimens portent à trois le nombre de spécimens connus. Enfin, ces spécimens contribuent à une meilleure compréhension de la morphologie de ce représentant du phylum problématique des Vetulicolia.

\section{Mots-clefs :}

- préservation de type Schistes de Burgess ;

- Great Basin ;

- Vetulicolia ;

- Miaolingien ;

- Drumien :

- Problematica

${ }^{1}$ Biodiversity Institute, University of Kansas, Lawrence, KS 66045 (USA)

2 jkimmig@ku.edu

3 wade.leibach@ku.edu

${ }^{4}$ Department of Ecology and Evolutionary Biology, University of Kansas, Lawrence, KS 66045 (USA) blieber@ku.edu

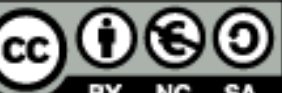

Published online in final form (pdf) on May 30, 2020

[Editor: Brian PRATT; French language editor: Bruno FERRÉ; technical editor: Bruno GRANIER] 


\section{Introduction}

The Cambrian of Utah preserves some of the most diverse soft-bodied faunas in the world and offers a unique view into Cambrian biodiversity (ROBISOn et al., 2015; Foster \& GAINES, 2016; LeROSEY-AUBRIL et al., 2018, 2020; KIMMIG, 2019; Kimmig et al., 2019). The Marjum Formation (Drumian-Guzhangian) preserves one of the youngest Cambrian soft-bodied biotas in North America, together with the Wheeler and Weeks Formations of western Utah, the Canadian Rockslide Formation of the Northwest Territories, and the McKay Group of British Columbia (KIMMIG \& PRATT, 2015; ROBISON et al., 2015; FOSTER \& GAINES, 2016; LEROSEY-AUBRIL et al., 2017; 2018, 2020; KIMMIG, 2019). The Marjum biota preserves at least 121 species, the majority arthropods. Deuterostomes, in comparison, are fairly rare, with only three echinoderms, two pterobranchs, and an eldoniid previously found in the Marjum Formation (RoBISON et al., 2015; Foster \& GAINES, 2016).

Here we describe the first Skeemella clavula BRIGGs et al., 2005, specimens from the Marjum Formation of Utah. This discovery not only extends the geographic range of the species, but also marks the first occurrence of Vetulicolia in the Marjum Formation. Moreover, previously S. clavula had only been known from a single specimen.

\section{Geological background}

The Marjum Formation is a local unit restricted to the House Range of western Utah. It ranges in age from the upper Ptychagnostus atavus Biozone to the lower Leopyge laevigata Biozone, and is up to $430 \mathrm{~m}$ thick (Foster \& GAINES, 2016). The Marjum Formation was deposited in subtropical environments north of the equator on the passive margin of the Laurentian craton, and represents an embayment filling succession comprised of thin-bedded limestones, interbedded shales, and mudstones (ROBISON, 1964; BRETT et al., 2009; FOSTER \& GAINES, 2016). It conformably overlies the Drumian Wheeler Formation and is in turn conformably overlain by the Guzhangian Weeks Formation (FosTeR \& GAINES, 2016). The Marjum Formation is correlative with: the Pierson Cove Formation in the Drum Mountains, Wah Wah Mountains, Fish Springs Range, and Dugway Range; the upper Limestone of the Cricket Mountains; and the upper Abercrombie Formation and Young Peak Dolomite in the Deep Creek Range (Fig. 1; FOSTER \& GAINES, 2016).

The Skeemella specimens come from just north of a locality referred to as Red Wash (Fig. 1.C). This locality is one of several Marjum Formation localities that preserve soft-bodied fossils (Foster \& GAINES, 2016). The Marjum Formation not only preserves a diverse soft-bodied biota, but also abundant trilobites and echinoderms (Robison et al., 2015; Foster \& GAINES, 2016).

\section{Materials and methods}

The described specimens were collected by Arvid AASE and are housed in the Division of Invertebrate Paleontology, Biodiversity Institute, University of Kansas (KUMIP). Specimens with the prefix UU are housed in the Department of Geology and Geophysics, University of Utah.

Specimens were imaged using an Olympus SZX16 microscope. Whole specimen images were created by stitching together mosaics of smaller images using Adobe Photoshop. The colour, contrast, and brightness of the images was adjusted using Adobe Photoshop 2020 v. 21.0.3.

\section{Systematic palaeontology}

\section{Phylum Vetulicolia SHU et al., 2001 Class Banffozoa CARon, 2006 \\ Order Banffiata ALDRIDGe et al., 2007 Family Banffidae CARON, 2006}

\section{Genus Skeemella BrIGgs et al., 2005}

Diagnosis: As for species

\section{Skeemella clavula Briggs et al., 2005}

(Figs. 2 - 3)

2005 Skeemella clavula Briggs et al., p. 682, Fig. 1.AC.

2015 Skeemella clavula; RoBison et al., p. 72, Fig. 197. 2016 Skeemella clavula; FOSTER \& GAINES, p. 311, Fig. 20.G.

Holotype: KUMIP 310501 (part, Fig. 3.A); UU 04083.01 (counterpart, Fig. 3.B)

Material: KUMIP 314102 (Fig. 2.A-C); KUMIP 314103 (Fig. 2.D)

Diagnosis: Bipartite, cuticularized body. Short, wide head shield-like anterior region divided longitudinally, with straight dorsal margin, curving ventral margin, and made up of nine segments separated by thinner membranes. Narrow vermiform posterior region of 43 segments, tergites separated by flexible membranes, terminating in an elongate unsegmented flattened structure that projected posteriorly into two spines (from BRIGGS et al., 2005).

Occurrence: 'Middle' Marjum Formation, Cambrian (Miaolingian, Drumian), Ptychagnostus punctuosus Biozone; House Range, north of Red Wash, west side of hill, NE $1 / 4$ SW $1 / 4$ NW $1 / 4 \mathrm{sec}$. 24 T17S, R13W, Millard County, Utah, USA, 39० $18^{\prime} 57.6^{\prime \prime N}, 113^{\circ} 16^{\prime} 12.0^{\prime \prime W}$. Lowermost Pierson Cove Formation, Cambrian (Miaolingian, Drumian), middle Ptychagnostus atavus Biozone; Drum Mountains, Cen. S 1/2 NE 1/4 sec. 20 T15S R10W, Millard County, Utah, USA, 39०30'10.8"N, $112^{\circ} 59^{\prime} 27.6^{\prime \prime} \mathrm{W}$. 
A

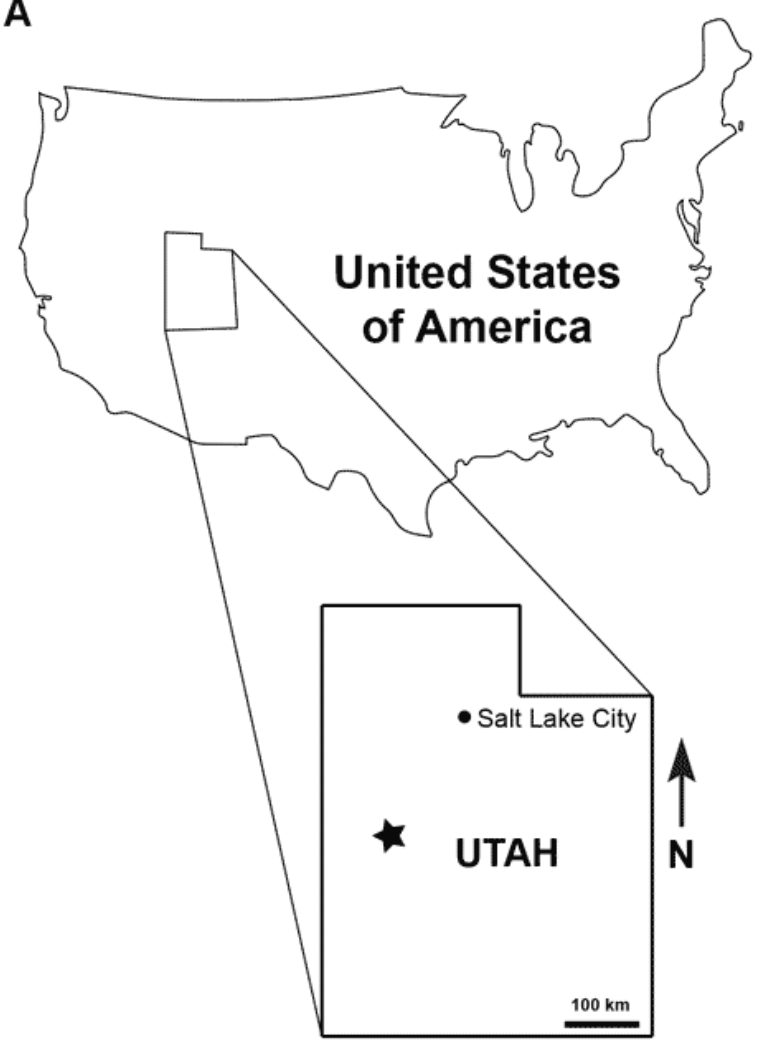

B
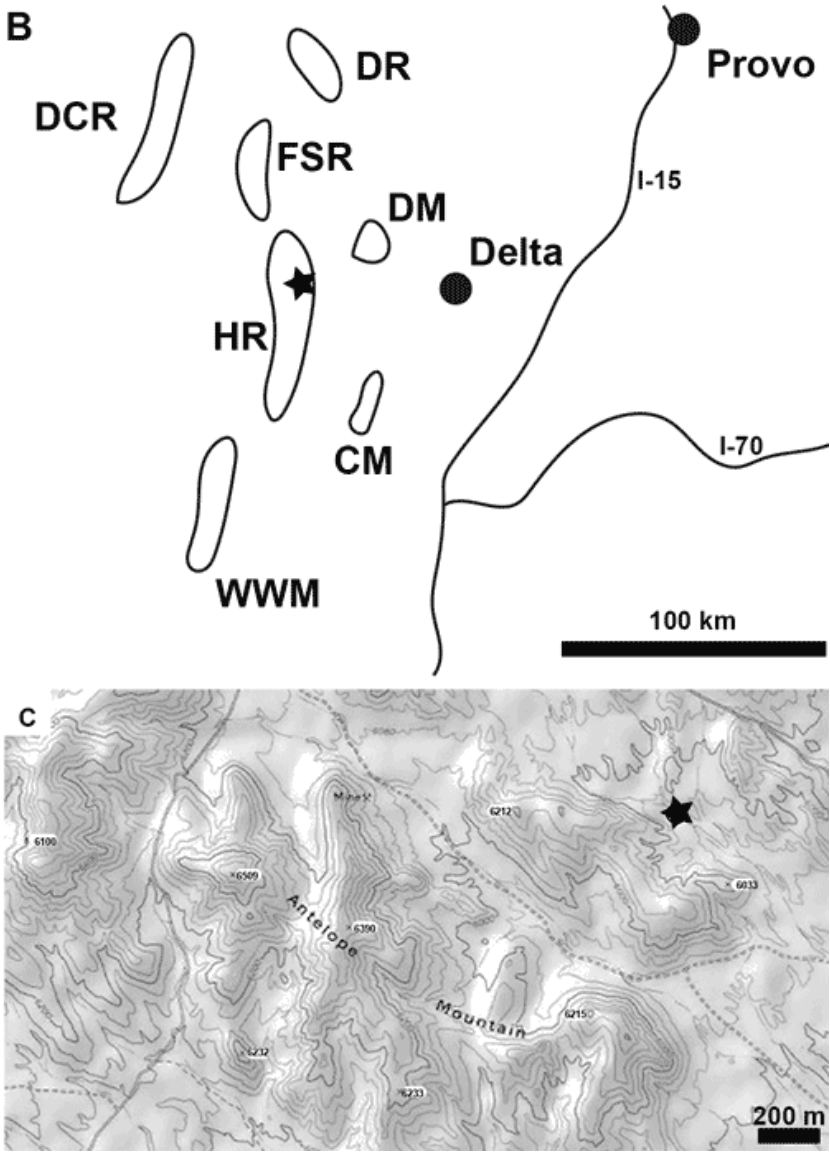

Figure 1: Approximate location of the Marjum Formation locality (asterisk; $39^{\circ} 18^{\prime} 57.6^{\prime \prime} \mathrm{N}, 113^{\circ} 16^{\prime} 12.0^{\prime \prime}$ ), House Range, north of Red Wash, west side of hill, Millard County, Utah, USA. A. Generalized location. B. Generalized regional map showing the major mountain ranges preserving Cambrian fossils (modified from FosteR \& GAINES, 2016). C. Topographic map. $C M=$ Cricket Mountains; $\mathrm{DCR}=$ Deep Creek Range; $\mathrm{DM}=$ Drum Mountains; $\mathrm{DR}=\mathrm{Dugway}$ Range; FSR = Fish Springs Range; HR = House Range; WWM = Wah Wah Mountains.

Description: KUMIP 314102 is a nearly complete specimen preserved in lateral view, missing parts of the posterior divisions, the posterior termination and parts of the anterior section. The anterior section of the body is sub-rectangular in outline, with a strongly convex ventral margin and a slightly convex dorsal margin. The anterior part of the specimen is $3.2 \mathrm{~mm}$ long and has a maximum height of $4.0 \mathrm{~mm}$. No longitudinal divisions are visible. The anteroventral edge of the cuticle of the first segment of the posterior section of the body appears to attach directly to the cuticle of the anterior section of the body. A total of 38 divisions are preserved; the posteriormost part of this section, including the bifid terminal segment known from the holotype (Fig. 3.B), is missing. The divisions vary slightly in size throughout the specimen, but this appears to be due to compaction. The posterior part of the specimen is $34.3 \mathrm{~mm}$ long and has a maximum width of $1.9 \mathrm{~mm}$
KUMIP 314103 preserves only about 9 divisions of the posterior cuticle. The specimen is 9.4 $\mathrm{mm}$ long and has a maximum width of $1.9 \mathrm{~mm}$.

Neither specimen preserves appendages, traces of a gut, or other interior organs.

Remarks: The described specimens are assigned to S. clavula based on the sub-rectangular anterior section of the body cuticle of KUMIP 314102 and the segmented posterior section of the body cuticle in both specimens. While the specimens are significantly smaller than the holotype (Fig. 3.A-B) from the Pierson Cove Formation described by BRIGGS et al. (2005), they have generally similar proportions of the anterior relative to the posterior sections of the body. The anterior part is about two times as high (wide) as each posterior division in KUMIP 310501 and KUMIP 314102 (Figs. 2.A-C - 3.A). In addition, posterior divisions in all three specimens have an average width to length ratio of about $3: 1$ (Figs. 2.A-D 3.A-B). 


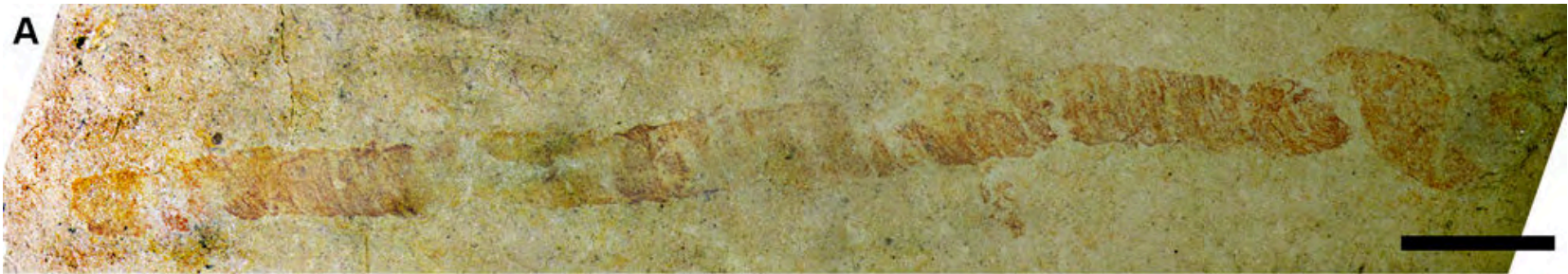

B
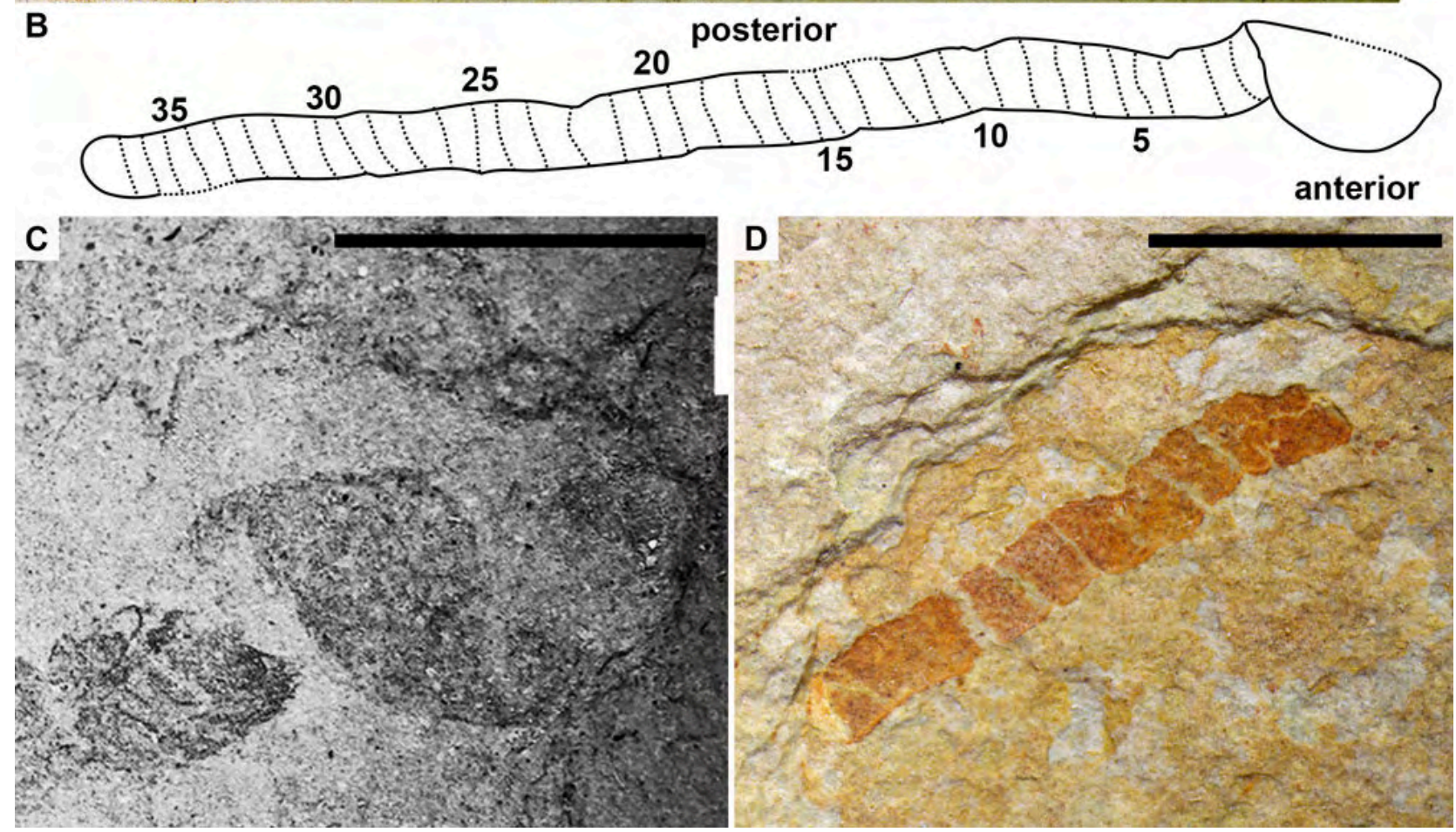

Figure 2: Skeemella clavula from the Marjum Formation (Cambrian, Miaolingian, Drumian), north of Red Wash, Millard County, Utah, USA. A. The most complete specimen (KUMIP 314102), preserving the anterior cuticle and 38 segments of the posterior cuticle. B. Interpretive drawing of KUMIP 314102. C. Close-up of the anterior region of KUMIP 314102. D. KUMIP 314103, preserving 9 divisions of the posterior part of the specimen. Scale bars are $5 \mathrm{~mm}$.

KUMIP 314102 differs from the holotype in a few features. For instance, punctuate ornamentation is preserved on both the anterior and posterior part of the Marjum specimen (Fig. 2.A, 2.C), whereas it is entirely absent on the holotype. The ornamentation is more pronounced on the anterior section of the body. The ornamentation might represent ontogenetic or preservational variation. Given that the material from the Marjum is generally less well preserved than the holotype the latter may be less likely. However, it could be that what is visible in KUMIP 314102 is the outer part of the cuticle, whereas the holotype might preserve the inner part. Perhaps notably, the punctuate ornamentation is also visible on the other specimen from the Marjum Formation (Fig. 2.D). Another difference between the holotype and the material from the Marjum Formation is that in the case of the latter the individual segments in the posterior section of the body are relatively shorter and broader. Again, this is likely an ontogenetic, not taphonomic, difference.

The posterior section of the specimen attaches directly to the anterior section in KUMIP 314102, suggesting that the separation in the holotype might be post-mortem. Unfortunately, neither new specimen shows the bifid posterior termination preserved in the holotype, as the posteriormost part of the posterior section is missing from KUMIP 314102, and only parts of the posterior section are preserved in KUMIP 314103.

The Marjum specimens do appear to be preserved under slightly different taphonomic conditions relative to the holotype, as the former preserve no relief. Moreover, the material from the Marjum may have experienced a longer period of decay prior to entombment, in parallel to the situation documented in other deposits (KIMmIg \& PratT, 2016; PATES et al., 2019). Perhaps as a result of these taphonomic differences, the anterior section of the specimen from the Marjum Formation is not differentiated into regions of upper and lower cuticle. Although CONWAY MORRIS et al. (2015) and RoBison et al. (2015) treated Skeemella clavula as occurring in the Wheeler Formation, the type specimen is actually from the lower part of the overlying Pierson Cove Formation (BRIGgs et al., 2005). 

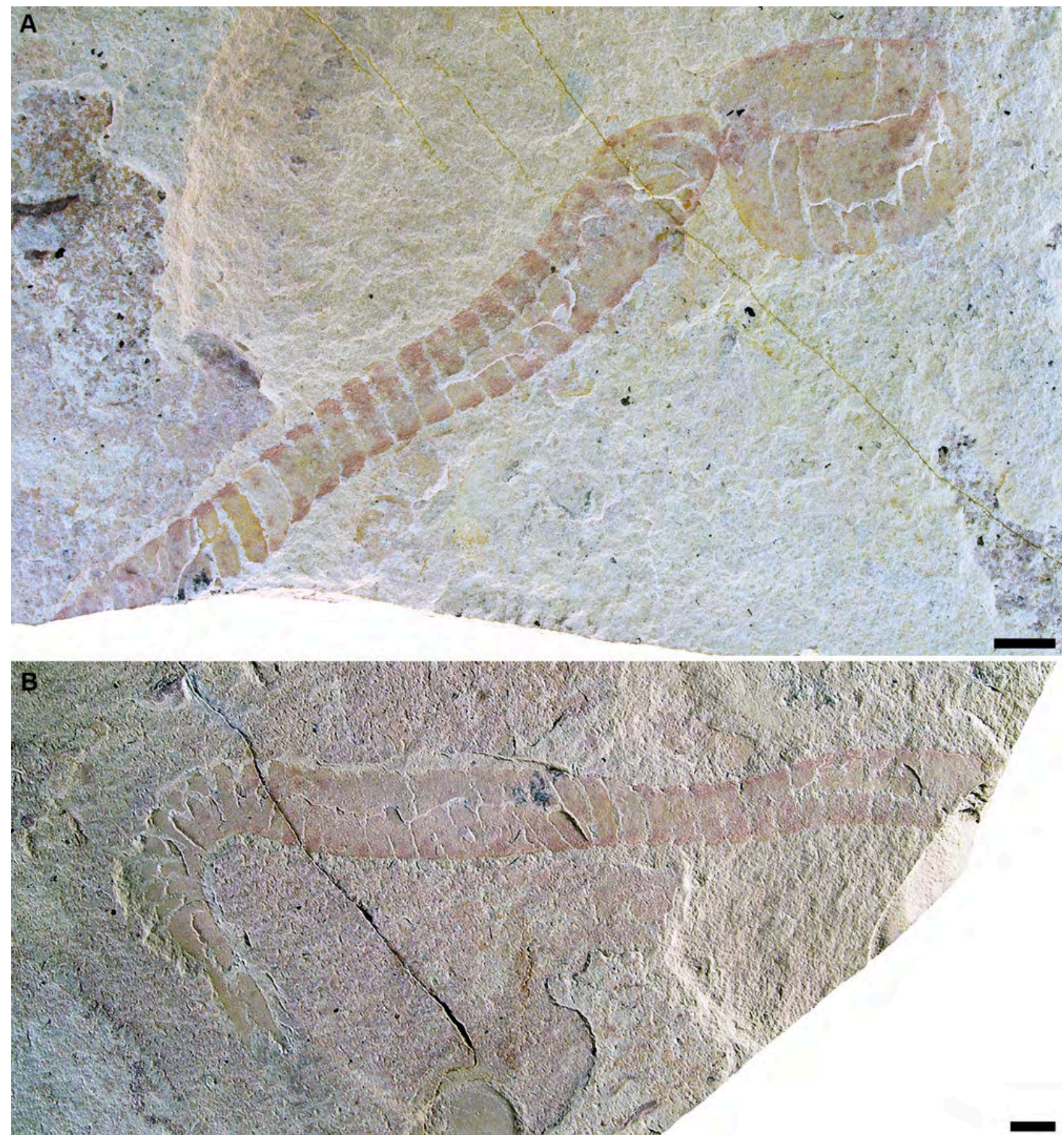

Figure 3: Part and counterpart of the holotype of Skeemella clavula from the lowermost Pierson Cove Formation (Cambrian, Miaolingian, Drumian), Drum Mountains, Millard County, Utah, USA. A. KUMIP 310501, lateral view of the anterior section and portion of the posterior section. B. UU 04083.01, lateral view of posterior section.

\section{Discussion}

BRiggs et al. (2005) only questionably assigned Skeemella clavula to the Vetulicolia, as the holotype lacks the five pairs of gill slits (instead there are eight) and a large frontal mouth is not preserved; the posterior section of the body also has dramatically more segments than was held to be typical of vetulicolians (however, with CARON's (2006) conclusion that Banffia is a vetulicolian, the latter difficulty was obviated). SHU (2005) and SHU et al. (2009) argued that S. clavula should not be treated as a vetulicolian because of these aforementioned character differences. SHU (2005) argued further that the extremely long posterior part of $S$. clavula suggested that it more likely represents an arthropod than a deuterostome. Notably, BRIGgs et al. (2005) suggested that $S$. clavula might necessitate re-evaluating whether vetulicolians represented deuterostomes or instead showed ecdysozoan affinities.

In contrast to SHU (2005) and SHU et al. (2009), AldRIDGe et al. (2007) argued that S. clavula was indeed a vetulicolian and belonged within the Banffidae, based on the presence of the 
cuticularized bipartite body, the carapace-like anterior body with a longitudinal division, the narrow segmented posterior body arising from the postero-dorsal margin of the anterior body, and the absence of evidence of eyes or appendages.

If $S$. clavula were to be regarded as an arthropod, as suggested by SHU (2005), it would have to be interpreted as consisting of a bivalved carapace, and a very long segmented thorax bearing posterior bifid rami. Further, the V-shaped indentations along the longitudinal break in the head shield of the holotype (Fig. 3.A) would have to be interpreted as poorly preserved appendages. Then in this case the headshield of the holotype would preserve the inside of the left valve and a broken right valve missing the ventral part. The divisions on the ventral portion of the headshield would thus represent potential appendages. This would moreover suggest that the right valve must be viewed as having broken twice. Then in addition KUMIP 314102 would have to be interpreted as preserving a partial right valve, which broke on the dorsal part.

Militating against the arthropod hypothesis, we note that the length of the thorax would be unusually long for an arthropod, considering the holotype preserves 43 divisions and KUMIP 314102 preserves 38 divisions. Additionally, the interpreted ventral opening of the divisions (BRIGGs et al., 2005) is unlike those found in any arthropod (Presumably an arthropod interpretation would require that these divisions be preserved under unique and highly distinctive taphonomic circumstances that at present remain indeterminate). However, it is worth noting that the Marjum specimens do not preserve cuticles with rounded terminations on both sides of the divisions, which could be due to the taphonomic pathway and the overall poorer preservation in the Marjum relative to the Pierson Cove. Lastly, it is true that the bifid rami preserved in the holotype (Fig. 3.B) are similar to those found in other Cambrian bivalved arthropods, e.g., Canadaspis and Perspicaris (BRIgGS, 1977, 1978; LIEBERMAN, 2003; KIMMIG \& PRATT, 2015), and are by contrast not known from other vetulicolians.

The new material unfortunately offers little to support (or revise) an assignment of Skeemella to the vetulicolians, and thus we follow the interpretations of BRIGGS et al. (2005) and ALDRIDGE et al. (2007) and assign it to the vetulicolians. However, the confirmed presence of Skeemella in the Marjum Formation, and ongoing field work in both the Marjum and Pierson Cove formations, will hopefully yield further specimens that might be able to resolve its biologic affinities.

\section{Conclusion}

The new Skeemella clavula specimens from the Marjum Formation represent the first probable vetulicolian specimens from the House Range of Utah, and extend the range of this taxon geographically. The precise age relationships between the lower part of the Pierson Cove Formation and this part of the Marjum Formation have not yet been determined, but it is possible that the new material also somewhat extends the species' distribution in time, with a range from Ptychagnostus atavus Biozone to P. punctuosus Biozone.

\section{Acknowledgments}

We thank Arvid AASE for donating specimens KUMIP 314102 and 314103, Holly and Ken SKEEM for donating specimen KUMIP 310501, Anna WHITAKER for assistance with photography, Rudy LEROSEY-AUBRIL for discussions of the Marjum Formation, and Derek BRIGGS and Quintin SAHRATIAN for the pictures of UU 04083.01. Reviewers Stephen PATES and Jean VANNIER, and handling editor Brian PRATT are thanked for comments that improved the manuscript. Editor Bruno GRANIER is thanked for his assistance with the manuscript.

\section{Bibliographic references}

Aldridge R.J., Hou X.-G., Siveter D.J., Siveter D.J. \& GABBOTT S.E. (2007).- The systematics and phylogenetic relationships of vetulicolians.- Palaeontology, vol. 50, p. 131-168.

BRIGGS D.E.G. (1977).- Bivalved arthropods from the Cambrian Burgess Shale of British Columbia.- Palaeontology, vol. 20, p. 595-621.

BRIGGS D.E.G. (1978).- The morphology, mode of life, and affinities of Canadaspis perfecta (Crustacea: Phyllocarida), Middle Cambrian, Burgess Shale, British Columbia.- Philosophical Transactions of the Royal Society of London (Series B), vol. 281, p. 439-487.

Briggs D.E.G., Lieberman B.S., Halgedahl S.L. \& JARRARD R.D. (2005).- A new metazoan from the Middle Cambrian of Utah and the nature of the Vetulicolia.- Palaeontology, vol. 48, p. 681-686.

Brett C.E., Allison P.A., DeSantis M.K., Liddell W.D. \& KRAMER A. (2009).- Sequence stratigraphy, cyclic facies, and lagerstätten in the Middle Cambrian Wheeler and Marjum Formations, Great Basin, Utah.- Palæogeography, Palæoclimatology, Palæoecology, vol. 277, p. 9-33.

CARON J.B. (2006).- Banffia constricta, a putative vetulicolid from the Middle Cambrian Burgess Shale.- Transactions of the Royal Society of Edinburgh: Earth Sciences, vol. 96 (for 2005), p. 95-111. 
Conway Morris S., Halgedahl S.L., Selden P. \& JARRARD R.D. (2015).- Rare primitive deuterostomes from the Cambrian (Series 3) of Utah.Journal of Paleontology, vol. 89, p. 631-636.

Foster J.R. \& GAINES R.R. (2016).- Taphonomy and paleoecology of the "middle" Cambrian (Series 3) formations in Utah's west desert: Recent finds and new data. In: COMER J.B., InKenbrandt P.C., KrahuleC K.A. \& Pinnell M.L. (eds.), Resources and geology of Utah's West Desert.- Utah Geological Association Publication, Salt Lake City, vol. 45, p. 291-336.

Kimmig J. (2019).- Burgess Shale Fauna. In: ALDERTON D. (ed.), Encyclopedia of Geology 2nd Edition.- Reference Module in Earth Systems and Environmental Sciences. URL: https://doi. org/10.1016/B978-0-12-409548-9.12019-6

KimMig J. \& PRATT B.R. (2015).- Soft-bodied biota from the middle Cambrian (Drumian) Rockslide Formation, Mackenzie Mountains, northwestern Canada.- Journal of Paleontology, vol. 89 , p. 51-71.

Kimmig J. \& PRATT B.R. (2016).- Taphonomy of the middle Cambrian (Drumian) Ravens Throat River Lagerstätte, Rockslide Formation, Mackenzie Mountains, Northwest Territories, Canada.Lethaia, vol. 49, p. 150-169.

Kimmig J., Strotz L.C., Kimmig S.R., Egenhoff S.O. \& Lieberman B.S. (2019).- The Spence Lagerstätte: An important window into Cambrian biodiversity.- Journal of the Geological Society, London, vol. 176, p. 609-619.

Lerosey-Aubril R., Paterson J.R., GibB S. \& ChatTERTON B.D.E. (2017).- Exceptionally-preserved late Cambrian fossils from the McKay Group (British Columbia, Canada) and the evolution of tagmosis in aglaspidid arthropods.- Gondwana Research, vol. 42, p. 264279.

Lerosey-Aubril R., Gaines R.R., Hegna T.A., Ortega-Hernández J., Van Roy P., Kier C. \& Bonino E. (2018).- The Weeks Formation Konservat-
Lagerstätte and the evolutionary transition of Cambrian marine life.- Journal of the Geological Society, London, vol. 175, p. 705-715.

Lerosey-Aubril R., Kimmig J., Pates S., SkABelund J., Weug A. \& Ortega-Hernández J. (in press).New exceptionally-preserved arthropods from the Drumian Wheeler Konservat-Lagerstätte of the House Range of Utah.- Papers in Palaeontology (23 April 2020). URL: https://doi.org/ 10.1002/spp2.1307

LiEBERMAN B.S. (2003).- A new soft-bodied fauna: The Pioche Formation of Nevada.- Journal of Paleontology, vol. 77, p. 674-690.

Pates S., Daley A.C., Edgecombe G.D., Cong P.-Y, \& LiEBERMAN B.S. (2019).- Regional radiodont replacements in the southern Great Basin, USA during the upper Dyeran (Cambrian Series 2, Stage 4).- Papers in Palaeontology, vol. 5, p. $1-28$

RoBISON R.A. (1964).- Upper Middle Cambrian stratigraphy of western Utah.- Geological Society of America Bulletin, vol. 75, p. 9951010.

ROBISON R.A., BABCOCK L.E. \& GUNTHER V.G. (2015).- Exceptional Cambrian fossils from Utah: A window into the age of trilobites.Utah Geological Survey, Salt Lake City, Miscellaneous Publication, vol. 15-1, 97 p.

SHU D.-G. (2005).- On the phylum Vetulicolia.Chinese Science Bulletin, vol. 50, p. 23422354.

SHU D.-G., CONWAY MORRIS S., ZHANG Z.-F. \& HAN J. (2009).- The earliest history of the deuterostomes: The importance of the Chengjiang Fossil-Lagerstätte.- Proceedings of the Royal Society B, vol. 277, p. 165-174.

Shu D.-G., Conway Morris S., HaN J., Chen L., ZHANG X.-L., ZHANG Z.-F., LIU H.-Q., LI Y. \& LIU J.-N. (2001).- Primitive deuterostomes from the Chengjiang Lagerstätte (Lower Cambrian, China).- Nature, vol. 414, p. 419-424. 